\title{
Analysis on Cultural Characteristics and Art Development of Dunhuang Dance Art
}

\author{
Jia Yang \\ Sichuan Normal University \\ Chengdu, China
}

\begin{abstract}
The author has made some thinking on the cultural characteristics and art development of Dunhuang dance art. This article analyzes the cultural characteristics of the Dunhuang dance, and points out that Dunhuang dance has the common character of popular aesthetics characteristics, and the freedom and unrestrained spirit of the image and the rational and compassionate feelings, and analyses the regeneration of the modelling art form in the Dunhuang dance, proposes the regeneration of the Dunhuang dance pose, as well as the regeneration of Dunhuang dance pose and the regeneration of the form. This article also analyzes the unique charm of Dunhuang dance art regeneration. It makes the elaboration from the three aspects of abundant aesthetic style and experience and the combination of modern art techniques and traditional culture, and the aesthetic space development of the Dunhuang dance with human as the medium. Finally, it proposes the opinions on the basic concept of Dunhuang dance art development, and considers that it should be made thinking from two aspects of creative thinking and technological development, commercialization development.
\end{abstract}

Keywords-Dunhuang dance; cultural characteristics; art development

\section{INTRODUCTION}

Dunhuang dance is originated from Dunhuang grotto frescoes, is the new type classical dancing created by China dance art workers in combination with resurrection of historical materials. It is different from the body rhyme genre and Han and Tang dynasties genre in the classical dancing, therefore, the dance academic circle considers that it is classical genre Dunhuang dance. With deep excavation and reengineering of China dance artists to the Dunhuang frescoes, the graceful Dunhuang frescoes in the static state has been continuously regenerating to be the unique dynamic art form of Dunhuang dance. That is to say, according to the native art data such as Dunhuang grotto frescoes, grottoes colorful frescoes and grottoes unearthed literature as the material is the new art form created by the artist with using the modern artistic thinking and dance creation technique. Dunhuang dance is the perfect combination of traditional culture and modern art and continuously exceeds and develops, when static Dunhuang frescoes to regenerate into dynamic Dunhuang dance art form is also greatly enhancing the value of Dunhuang culture, deepens the research of Dunhuang studies. In the overall background of the global economic and cultural integration, today we deeply excavate and remodel China classic art culture, especially the In-depth research on primordial, regeneration of Dunhuang art is great significance. At the same time, the successful performance of the "Dunhuang dream"," Silk Road Flower Rain "and other large national quality dance drama based on the based on the background of Dunhuang theme Inspires people to the great interest in Dunhuang culture, also makes more people paying close attention and thinking about the further development of the Dunhuang dance. The article makes some thinking on the cultural characteristics and art development analysis of Dunhuang dance art.

\section{THE CUlTURAL CHARACTERISTICS OF DUNHUANG DANCE}

\section{A. Common Characteristics of the Popular Aesthetics}

Dunhuang mogao grottoe is a huge art treasure house of dance, music, fine arts. Almost all the caves are reserved dance pattern of rich modelling. It is rich dance image in the Dunhuang frescoes, which inspires the artistic inspiration in China modern dance artists, such as "the heavenly maids scatter blossoms" created by the famous Peking Opera artist; Mei Lanfang is based on Dunhuang frescoes [1]. When Mei Lanfang created the works, he referred to the image of all sorts of flying Apsaras in the Dunhuang frescoes, cancelled the shake sleeve in the original clothing, and changed it to two long silks, strived to perfectly display the flying Apsaras image in the fresco. The performance of work got a great sensation and recognition, is the art work of China in the earlier time based on Dunhuang fresco art. Seen from the layout of the Dunhuang frescoes, it refers to the methods of western perspective, there are Buddha land heavenly music on the top, and folk songs and dances on the bottom, in which, it includes a lot of myths and legends, with line art as the main structure. Created by the ancient painter art, it is architected the different standard and a well-organized form characteristics. In general, it presents the soul-stirring and amazing of the extensive and profound rich connotation characteristics. That is the grand details of the Dunhuang dance creation. Dunhuang fresco is the product of religious period. The creation of Dunhuang dance vocabulary also has strong natural religious color. The artists interpret Buddhist philosophical connotations through the dance modelling, develop and expand the compassionate feelings, objectively meet and reflect the general public common aesthetic ideal, had a positive aesthetic empathy. 


\section{B. Flying Apsaras's Image of A Free Spirit}

The image of flying Apsaras in the Dunhuang mogao grottoes can be seen everywhere, with freedom, elegant, and bold and unrestrained artistic visual impact. Flying Apsaras is originally from Buddhist art, represents Heaven palace god and xiāngyīn Xiangyin god [2]. In the nearly five hundred caves in the Mogao grottoes, there are more than two hundred caves which have flying Apsaras statues. They are in different attitude, full of spirit and energy; around the statue of painted sculpture alongside. It can be seen that in the changes of thousand years, almost every dynasty all had the different flying Apsaras image, and its modelling was continuous evolvement with the change of the history and culture. The aesthetic characteristic of the Dunhuang flying Apsaras lies in "flying without wings", and lies in the expression of "freedom". The production and development of this particular image of flying Apsaras in Dunhuang frescoe has concentrated the energy and efforts of the artists in different periods, shows the unique expressive force and culture deposits of ancient painting art, and shows the yearning and desire of the ancient artists for freedom. In the art of "flying Apsaras" space, it is based on freedom as the aesthetic basis, at the same time, embodies the highly praise to the human nature itself to the art spirit, and the artistic conception of refutation to the feudal ethics, and thought, spiritual freedom and bold and unrestrained. From this, it generates the modelling design and performance of flying Apsaras in the Dunhuang dance embodies the romantic charm of the frescoes in the flying Apsaras, also vividly expresses the traditional Chinese aesthetics characteristics, especially the pursuit of aesthetics of the artistic conception Intergeneration in the Chinese dance aesthetics

\section{Rationality and Compassionate Feelings of Dunhuang Dance}

Since Buddhism was introduced into China, it is connected with China traditional rites and music. Dunhuang culture not only inherits the traditional culture of China, but also is the development and exploitation of Buddhist thought. The reveal of the Dunhuang frescoes to the traditional Chinese artistic spirit in essence is human survival and existence. Cultural spirit is not only a philosophical problem, but also belongs to the aesthetic problems [3]. And the culture and art reality displays the realization and awakening of human to the art g, also displays the artistic creativity. It can be said that culture and art represent the perceptual figurative side of the human spirit, also is the symbol of human beings continuously exceeding the experience to pursuit of perfection. As the art form of the perceptual and the rational combination, Dunhuang dance reflects the unity of spirit pursuit and discipline and regulation. As the form of dance of strong color of Buddhism, Dunhuang dance is not simply expounds the pursuit of Buddhism, but from the angle of modern art performance, shines the eternal bright rational radiance in the Buddhist culture. This rational spirit makes the art form of Dunhuang dance always keeping a clear direction, does not depend on the popular, and does not make a strained interpretation in the world. At the same time this kind of rational spirit also shows the respect and praise for life. In the pursuit of beauty, it reflects the strong passion of life. When we watch the graceful Dunhuang dance, feel that it is not just the interpretation for the niceness, but also is infiltrated in the profound Buddhist compassionate feelings.

\section{THE REGENERATION OF THE DUNHUANG DANCE MODELLING AND ART FORM}

The dance in the Dunhuang frescoes can be roughly divided into two major categories of Heaven palace and secular music, In the heaven palace moon skill music, it is divided into the heavenly palace skill music, flying Apsaras skill music, Dharma protector silk music and etc. Secular music can be divided into Buddhist pilgrim skill music and other several major categories. In short, there are flying Apsaras dance, heavenly palace skill dance, Buddha skill dance and other types It records and condenses the dance image in different periods of ancient time in China is also part of a page of thick and heavy colors in the cultural history of Chinese art. The emergence of the full-length dance drama "Silk Road Flower Rain" plays a vital role in promoting the formation of Dunhuang dance genres in China. In the following, through taking the full-length dance drama "Silk Road Flower Rain" as the example, the author briefly describe the regeneration of Dunhuang modelling and dance art form.

\section{A. The Regeneration of the Modelling of Dunhuang Dance}

Before the 1980s of last century, the common modelling of China dance is relatively single, except of having the popular dance form of the strong Cultural Revolution era color, the dances which has national culture characteristics was also very dull and poor. In order to rebuild the traditional culture of folk dancing, to break the rigid situation of the national dance and, some artists who had the responsibility were bearing the work of further absorbing material of Dunhuang mogao grottoes , actively explored the dance form of Chinese nation connotation. The broad ideological connotations and rich dance resources has become the nutrients source of artists to absorb. The vivid lively dancing posture of the dancers do not stick to one pattern, the clear pure and fresh and changeful modelling and elegant dance skirt, the wiggle wipes all constitute a beautiful picture which is greatly inspires the dance modelling creative inspiration of the dancing artists. The artists had made several in-depth research on Dunhuang, and collected absorbed and used for reference for the dancing postures of the dancers in the frescoes, and through the dynamic analysis to the dancing posture in the Dunhuang frescoes, conducted the modelling research from the aspects of rhythm, speed, direction and other aspects, such as conducted the repeated research on the still dancing posture of the dancers in the fresco, have concluded that the richness of dance line fluency and gesture in the Dunhuang frescoes and other modelling rule, combined with the traditional dance modeling concepts and vocabulary, intergraded the dance pose of the western regions and the central plains region eventually created the large dance drama "Silk Road Flower Rain" as the Dunhuang dance art form of the mature symbol. The success of the dance drama" Silk Road Flower Rain" laid the solid foundation for people afterwards for widely accepting and loving and popular Dunhuang dance. 


\section{B. The Regeneration in Dunhuang Dance Form}

The representation of the Dunhuang dance art form mainly is using the two ways.

One is dancing inheritance and innovation. The artists make reference to the dance native plain image of the dancers in Dunhuang frescoes and redesign the visual statue, in the dance modelling, clothing modelling, color, etc. of the dance image, and in smooth dancing posture line and gesture and other aspects, in the dance rhythm, speed, direction and so on of the dance rhythm, the artists have made the inheritance and innovation boldly, have formed a complete set of relatively mature dance pose, highlighted the fairy alike, elegant clever, mysterious and distant characteristics. Such as the dance drama "Silk Road Flower Rain" dance, the performers perform the solo dance, dance for two people, group dance, flying Apsaras dance and other unique distinctive modelling, the rich internal implication of the body shape, the extreme beautiful movement rhythm had the great impression, and got the audience widely praise and appreciation of the industry experts. Second, the overall dance design is harmony and unity. The artists should be first based on the stage performance of the in Dunhuang dance, with an emphasis on visual effect of art stage, with strong Buddhism color and full-bodied flavor architecture stage background music and stage of the Western Regions, achieve harmony and unity of the whole dance, form the visual impact and auditory shock of the dance, make Dunhuang dance, the unique and wonderful flower in the dance circle to radiate the charming luster. Such as the dance drama "Silk Road Flower Rain" is setting the different styles through eight stages, from various angles, showing the northwest scenery magnificent grand and luxurious palace interior. In the clothing design, it was mainly based on the tang dynasty clothing, focused to display the various kind of apparel modeling in the tang dynasty period. The stage music was using the traditional folk drama and living museum tune for the reference. On the development of the melody, it focused on transforms from, with freedom rhythm. In the melody, it had strong ethnic characteristics, and the beautiful dancing posture of the dancer is more showed the clever and poetry. The gorgeous dress, beautiful music, fantasy lights, flying Apsaras were leisurely coming, they are were dancing with wind from time to time, and sometimes bowed the hand and extended the arm, sometimes were scattered petals, brought people into the kingdom of heaven like a dream fairyland, and brought great artistic enjoyment to the audiences.

\section{The UniQue Charm OF THE DUNHUANG DANCE ART REGENERATION}

\section{A. Have Abundant Aesthetic Style and Experience}

There are unique styles of different periods reserved in Dunhuang frescoes, with ever-changing dance art form. There are some fairies leaning against the railing and overlooking, and some fairies freely flying Apsaras, and some heroic King Kong and some gentle and dignified Bodhisattva and etc. Since the Northern Liang, the Northern Wei Dynasty, the Western Wei Dynasty and the Northern Zhou Dynasty to Yuan dynasty, the integration of the different dancing arts of the different periods formed the system of different style dances accompanied by music. In the inheritance and evolution of thousands of years, the Dunhuang native art has been taking Chinese traditional culture as the soil, striving to absorb and to inherit. Due to the geographical position, it forms the type of integration of Chinese traditional culture and foreign culture, after then, Dunhuang dance also inherited the characteristics of later, and integrated into the content of era, and formed the striking and unique Dunhuang dance style. On this basis, Dunhuang dance also is integrated with Chinese classical dance elements, and has formed the rich dance steps and hand shape system. Compared with the dancing posture in the Dunhuang frescoes, the Dunhuang dance is reshaped based on the modern aesthetic and design, has become connotation rich, gentle and solid, and flexible and changeable, with rhythmic vitality, has rich China nationality colors, and presents the artistic charm beyond geographical, borders, so that has formed a rich and colorful art experience.

\section{B. The Combination of Modern Art Technique and Traditional Culture}

Dunhuang dance creation is integrated with the Chinese traditional ritual and music culture and Buddhist thought, also is added the concept elements of the epochal character. As the regeneration art, it finally is showing the profound culture connotation of Dunhuang based on the perspective of modernization, is the important inheritance and innovation to the of Dunhuang culture. In the Dunhuang frescoes the various forms of dancers and some dancing pattern with Chinese traditional culture color, not only is precipitation of the China traditional ritual and music culture, also represents the spiritual connotation of western Buddhism. The reflection of Chinese traditional Confucian culture and Buddhism culture in Dunhuang native art constitutes the cultural system of national characteristics. Due to long time, dynasties change, wars frequently, time lost, these culture is gradually being forgotten. Dunhuang dance is the developing and expanding as well as the remodeling of Dunhuang culture, and is the perfect combination of the traditional culture and art and modern culture. Its significance is very significant. What we see in the dance drama "Silk Road Flower Rain" is that in the form of dance, it shows the tang dynasty as the background reappears the multinational economic cultural blend scene of flourishing period of Tang Dynasty. On the basis of the showing Dunhuang native dance, it praises the human freedom, Human life genuine feeling reveals and denounces the evil and dark, embodies the spirit of The Times of peace and development, is also in the basis of inheriting Dunhuang native art, and reflects the era characteristic, realizes the perfect combination of traditional culture and modern art.

\section{The Aesthetic Space Expanded by Man-Made Media}

Dunhuang frescoes is originated from Dunhuang mogao grottoes, Dunhuang mogao grottoes which is located in the top of the bluff of east of Dunhuang Mingsha mountain. The artistic creation of painting and sculpture can only be made in the cavern where has been dug well to repair the four walls smooth and levelling. Due to these native art medium is made out of stone, wood and plaster, through rain erosion and other influence of natural environment, it is very easy to be damaged [5], combined with the influence of man-made destruction and 
other influences, the ecological art style in Dunhuang frescoes has fuzzy, even being protected, it is difficult to withstand the erosion of times and tide. And Dunhuang dance takes people as the media of art, and gives the life vitality to Dunhuang art. The dance is communicating the arts through the thought and emotional element, and takes the people as emotion and artistic symbol, compared with the Dunhuang frescoes, it is more flexible and changeable, and is more able to express thoughts and feelings incisively and vividly. The human body beauty in the dance art itself has the cultural characteristics. The presentation of human body to the dance is integrated into deep emotions, combined the beauty of dancing posture of the fresco and the human body dancing, it makes the Dunhuang culture vivid and sensible. As an art medium, Dunhuang dance is expressing the emotion with rich human movement, is just different from fresco and painted sculpture which convey emotion in line color, but is more able to show the emotional rhythm and change of the people, thus makes the audience producing strong emotional resonance. In the Dunhuang dance, the smooth dance movements and beautiful modelling, also has a unique sense of rhythm and emotional tension, is able to provide direct epic visual image to the audience. In short, the unique spread carrier and media of the Dunhuang dance is greatly expanding the aesthetic space of Dunhuang art.

\section{THE BASIC IdeA OF THE CURRENT Dunhuang DanCE ART DEVELOPMENT}

\section{A. Creative Thinking and Science and Technology Development}

Dunhuang art is a spirit dialogue beyond time and space of one thousand years, symbolizes the art pursuit of Huaxia national culture consciousness, is the great contribution of the Chinese nation to the world nation culture and arts academic circle, has far-reaching influence, and has great inspiration for later generations of modern art creation. For the development of Dunhuang dance art, we should focus on the big background of the globalization of economy and culture, and use the modern creative thinking, modern dance techniques to further excavate the development of Dunhuang art. The creative development of Dunhuang dance art requires constant innovation, dare to break through. On the brand resources development, with the help of the modern advanced science and technology, especially the digital technology, we should conform to the trend of internationalization of cultural industry development.

\section{CONClusion}

For the development and utilization of the Dunhuang dance art resources, we should combine with the actual market demand fully, make rational strategic planning, artistic originality implement the team market commercialization to create the culture brand, strive for the maximization of social benefits and economic benefits. For example, in the of the creative process of the "dance drama" "Dunhuang charm", the designer firstly developed the quality work development strategy through market research, and invited the expert at home and abroad to make the argumentation evaluation, and made the overseas markets as the main development direction, catered for the overseas market demand with the characteristic of Chinese traditional culture, eventually, succeeded in creating the quality fine repertoire integrated dancing, singing, and music, created quite a stir in the world. Combined with the dance drama "Silk Road Flower Rain" as a national representative of the artistic high-quality work, under the original brand effect, it is enduring popularity, as well as further enhanced its brand image, and continuously explored the combination of business and culture development path, with continuous innovation, created the derivative of the series of cultural products related to "Silk Road Flower Rain", such as cartoon modelling, artwork, books, discs and other products, formed to provide a system as the main body of the dancing art brand, further expanded the spreading scope of Dunhuang dance art, had a huge impact.

\section{REFERENCES}

[1] Mu Jiguang: Art regeneration: an important proposition of Dunhuang art history research $[\mathrm{J}]$. Journal of northwest normal university (social science edition), 2009 (01): 29-33.

[2] Han Wei: Research on Dunhuang art and its regeneration [J]. Journal of literature and art research, 2010 (4): 154-156.

[3] Zhubin: Reflection on Dunhuang art regeneration phenomenon in the contemporary context $[\mathrm{J}]$. Journal of Hainan normal university (social science edition), 2013 (05): 7-12.

[4] Liu Jie: Theory of Dunhuang art "regeneration" philosophical proposition and the development of contemporary Chinese Dunhuang genres [J], Gansu social science, 2014 (3) : 54-57.

[5] Yin Hong. Flying Apsaras and Dunhuang art regeneration [J], Journal of Zhengzhou university (philosophy and social sciences edition), 2015 (02): 184-189.

[6] Chen Ruirui, Shang Junrui: dance body language interpretation of Dunhuang flying Apsaras artistic image $[\mathrm{J}]$. Journal of Beijing dance academy, 2015 (04) : 20 to 24. 